\title{
What is the most effective treatment for frozen shoulder?
}

\author{
Amar Rangan professor of orthopaedic surgery ${ }^{123}$, Nigel Hanchard reader in orthopaedics ${ }^{4}$, Catriona \\ McDaid senior research fellow ${ }^{3}$
}

${ }^{1}$ The James Cook University Hospital, Middlesbrough TS4 3BW, UK; ${ }^{2}$ Nuffield Department of Orthopaedics, Rheumatology and Musculoskeletal Sciences, University of Oxford, Oxford OX3 7HE, UK; ${ }^{3}$ York Trials Unit, Department of Health Sciences, University of York, York YO10 5DD, UK; ${ }^{4}$ School of Health and Social Care, Teesside University, Middlesbrough TS1 3BX, UK

Frozen shoulder is a painful condition that most commonly affects people in their 50s, ${ }^{12}$ and may limit daily activities and disturb sleep. ${ }^{3}$ Its annual prevalence has been estimated as 1.4 per 1000 patients in a UK study of two general practices (total population 17000$).{ }^{4}$

The diagnosis is clinical (see box 1). Restriction or pain, or both, on shoulder elevation and external rotation have been consistently described in the literature, ${ }^{6-12}$ yet there are insufficient data to evaluate diagnostic accuracy of signs and symptoms. ${ }^{6}$ Restriction and pain are evident on passive as well as active testing, which differentiates it from rotator cuff disease (where passive movements are classically of full range). ${ }^{6}$ Another differentiator is crepitus in the shoulder, which is more indicative of arthritis. ${ }^{12}$ Three phases (pain, stiffness, and resolution) are described, but they often overlap. Patients may have "pain-predominant" or "stiffness-predominant" frozen shoulder. ${ }^{13}$

Although frozen shoulder is considered self limiting, long term longitudinal follow-up data are scarce. The largest longitudinal series to date (223 patients) showed that $41 \%$ of patients had persistent symptoms at a mean follow up of 4.4 years, but this was based in secondary care, where more severe and less tractable cases are likely to be seen. ${ }^{14}$ The same study found recurrence rare, but the other shoulder was affected in 6-17\% of patients within five years. ${ }^{14}$ Reported associations include diabetes, cardiovascular disease, trauma, stroke, neurosurgery, and thyroid disease.

Less invasive treatments are generally tried first, but earlier use of more invasive interventions, particularly surgical capsular release, is increasing (box 2) ${ }^{18}$ There is uncertainty as to when these should be offered, and their clinical and cost effectiveness.

\section{What is the evidence of uncertainty?}

There are large gaps in evidence for effectiveness of treatments for frozen shoulder. The systematic review we analysed (see box 3 ) included 28 randomised controlled trials, one quasi-experimental study, and two case series. ${ }^{15}$ There were insufficient studies with a similar intervention and comparator to quantify effectiveness. Most studies are at a high risk of bias; do not report adequate methods for randomisation, allocation concealment, and outcome assessment; and seem to be inadequately powered. Few studies report a consistent method for collection of data on harms. ${ }^{15}$

Overall, physiotherapy and intra-articular steroid injections have been shown to have some benefit. Although there is no convincing evidence to support other measures, we emphasise the absence of good evidence rather than evidence that these management options are ineffective (see table $1 \Downarrow$ ).

A systematic review of six randomised controlled trials comparing intra-articular corticosteroid injection with placebo and with manual therapy and exercise shows short term benefit with improvement in pain, function, and range of movement (up to 6-7 weeks) compared with placebo ${ }^{15}$ and possibly compared with manual therapy and exercise. ${ }^{19}$ This evidence suggests that a single corticosteroid injection for people with frozen shoulder of up to a year in duration may hasten improvements in pain and function by some weeks. There is moderate evidence for hydrodilatation-distension of the 


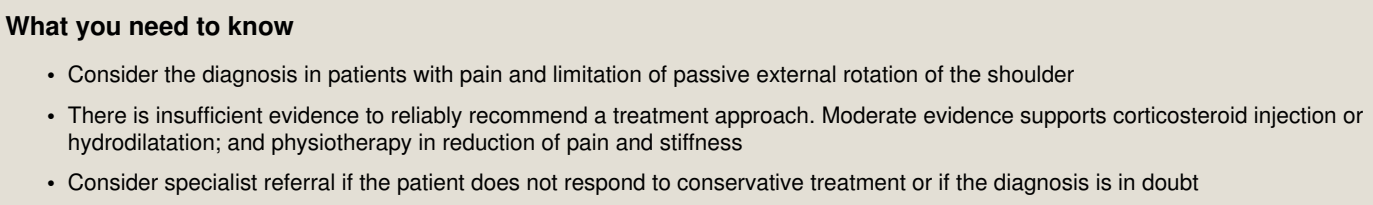

- Consider the diagnosis in patients with pain and limitation of passive external rotation of the shoulder

- There is insufficient evidence to reliably recommend a treatment approach. Moderate evidence supports corticosteroid injection or hydrodilatation; and physiotherapy in reduction of pain and stiffness

- Consider specialist referral if the patient does not respond to conservative treatment or if the diagnosis is in doubt

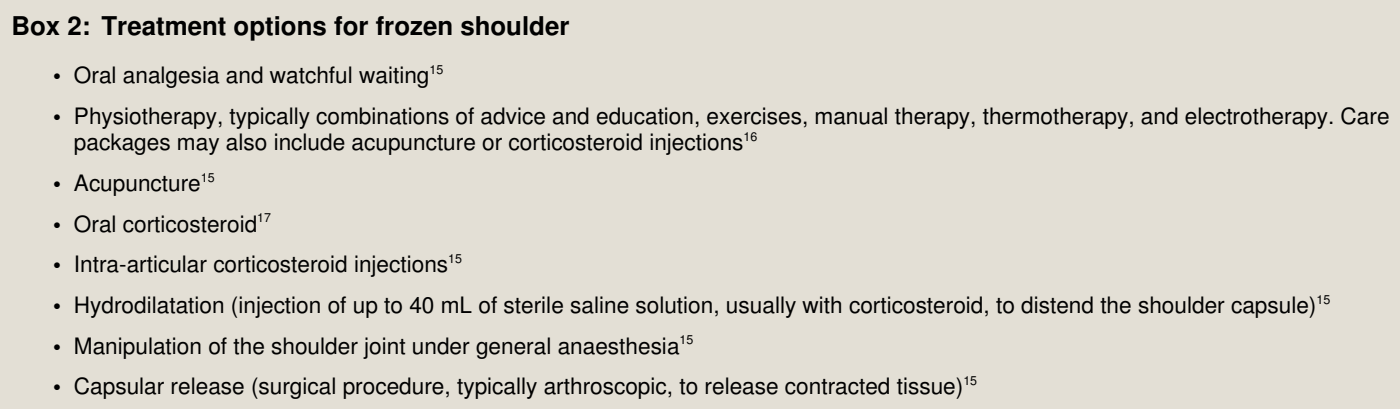

\section{Box 3: Search strategy and study selection}

We have referenced the most up to date systematic review, published in 2012, for individual treatment comparisons. ${ }^{15}$ We searched Medline for randomised controlled trials undertaken since then (up to May 2015) using the search strategy from the 2012 review combined with a validated filter for randomised controlled trials. We screened the results for new trials of manipulation under anaesthesia, capsular distension, and capsular release only, as physiotherapy interventions had been studied in Cochrane reviews published in 2014.

shoulder capsule with normal saline and corticosteroid—instead of a corticosteroid injection. ${ }^{15}$ Exercise and mobilisation may augment the effect of steroid injection for some outcomes, but there is insufficient evidence to reach a conclusion.

Designing trials and quantifying the efficacy of physiotherapy is fraught with difficulty. It is a complex intervention encompassing a range of physical techniques, advice, education, painkillers, thermal or electrotherapy, and steroid injection that may have varying efficacy and may be delivered in varying intensities. $^{8} 9$

Our updated Medline searches identified:

- A randomised trial of 64 patients comparing fluoroscopy guided anterior distension with ultrasonography guided posterolateral capsular distension ${ }^{21}$

- A randomised trial of 48 patients comparing ultrasonography guided and fluoroscopy guided capsular distension $^{22}$

- A four-armed study with 53 participants investigating intensive mobilisation techniques combined with capsular distension. $^{23}$

All the studies had a high risk of bias and seem to be inadequately powered.

\section{Is ongoing research likely to provide relevant evidence?}

We searched http://clinicaltrials.gov and the WHO International Clinical Trials Registry Platform and identified six ongoing randomised trials (table $2 \Downarrow$ ). These trials are likely to provide evidence on four commonly used current interventions-that is, intra-articular injection with physiotherapy, hydrodilatation, manipulation under anaesthesia, and capsular release.

\section{What should we do in light of the uncertainty?}

Communicate to patients that frozen shoulder is a benign and usually self limiting condition. Simple advice on activity modification and pain control may suffice (see box 4). Listen to the patient, and be prepared to adapt treatment, for example by referring on if their symptoms are not resolved or if the diagnosis is in doubt.

Consider referral for physiotherapy. Based on a survey of 289 UK physiotherapists, ${ }^{16}$ physiotherapy care for frozen shoulder includes advice and education, which patients consider crucial. ${ }^{30}$ In the pain-predominant stage, it is also likely to include an intra-articular steroid injection, a technique practised by many physiotherapists, and for which there is moderate evidence of effectiveness.

Current trends in practice involve escalation to more invasive treatments including manipulation under anaesthesia or arthroscopic capsular release, but there is insufficient evidence to recommend these. Although not clearly established, frozen shoulder may be associated with diabetes, and diabetic patients may be more resistant to treatment. ${ }^{22}$ 


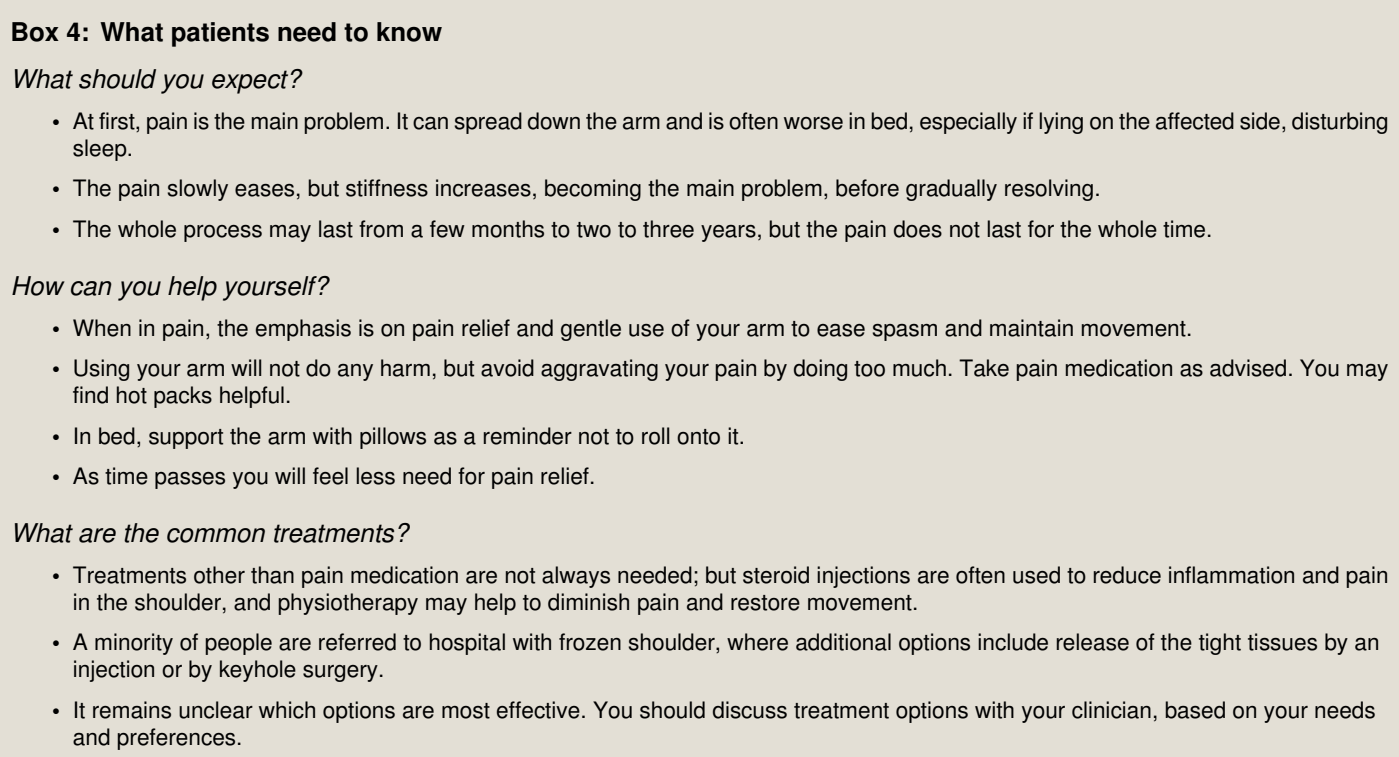

To address these uncertainties, it would be appropriate to encourage suitable patients to participate in trials designed to answer questions on which treatments are most effective (box $5)$.

We thank Helen Collin and Stanley West, our patient contributors to this article; and Lorna Goodchild, physiotherapist, for organising this aspect.

Contributors: The idea for this article was formulated by AR in discussion with M Chew (associate editor, BMJ). AR, $\mathrm{NH}$, and $\mathrm{CM}$ contributed to different sections of the article in preparation of the first draft. All authors approved the final version, and AR is the guarantor.

Competing interests: We have read and understood the BMJ policy on declaration of interests and declare the following interests: AR has received travelling expenses to attend meetings, consultancy fees, and educational grants from DePuy; and licence fees from JRI towards a pending UK and European patent on a shoulder prosthesis. AR is chief investigator, and $\mathrm{NH}$ and $\mathrm{CM}$ are co-investigators, for UKFROST. NH and $\mathrm{CM}$ do not have any other competing interests to declare.

Patient consent obtained.

1 van der Windt DA, Koes BW, de Jong BA, Bouter LM. Shoulder disorders in general practice: incidence, patient characteristics, and management. Ann Rheum Dis 1995:54:959-64 doi:10.1136/ard.54.12.959 pmid:8546527.

2 Walker-Bone K, Palmer KT, Reading I, Coggon D, Cooper C. Prevalence and impact of musculoskeletal disorders of the upper limb in the general population. Arthritis Rheum 2004;51:642-51. doi:10.1002/art.20535 pmid:15334439.

3 Dawson J, Shepperd S, Carr A. An overview of factors relevant to undertaking research and reviews on the effectiveness of treatment for frozen shoulder. Shoulder Elbow 2010;2:232-7doi:10.1111/j. 1758-5740.2010.00067.x.

4 Ostör AJ, Richards CA, Prevost AT, Speed CA, Hazleman BL. Diagnosis and relation to general health of shoulder disorders presenting to primary care. Rheumatology (Oxford) 2005;44:800-5. doi:10.1093/rheumatology/keh598 pmid:15769790.

5 Boyle-Walker KL, Gabard DL, Bietsch E, Masek-VanArsdale DM, Robinson BL. A profile of patients with adhesive capsulitis. J Hand Ther 1997;10:222-8. doi:10.1016/S0894-1130( 97)80025-7 pmid.9268913.

6 Walmsley S, Osmotherly PG, Rivett DA. Movement and pain patterns in early stage primary/idiopathic adhesive capsulitis: a factor analysis. Physiotherapy 2014;100:336-43. doi:10.1016/j.physio.2014.02.001 pmid:24680792.

7 Codman E. Rupture of the supraspinatus tendon and other lesions in or about the subacromial bursa. Boston, 1934.

8 Rundquist PJ, Anderson DD, Guanche CA, Ludewig PM. Shoulder kinematics in subjects with frozen shoulder. Arch Phys Med Rehabil 2003;84:1473-9. doi:10.1016/S0003-9993( 03)00359-9 pmid:14586914.

9 Rundquist PJ, Ludewig PM. Patterns of motion loss in subjects with idiopathic loss of shoulder range of motion. Clin Biomech (Bristol, Avon) 2004;19:810-8. doi:10.1016/j. clinbiomech.2004.05.006 pmid:15342153.

10 Wolf EM, Cox WK. The external rotation test in the diagnosis of adhesive capsulitis. Orthopedics 2010;33. doi:10.3928/01477447-20100329-11. pmid:20506951.

11 Noboa E, López-Graña G, Barco R, Antuña S. Distension test in passive external rotation: Validation of a new clinical test for the early diagnosis of shoulder adhesive capsulitis.
Rev Esp Cir Ortop Traumatol 2015;59:354-9. doi:10.1016/j.recote.2015.07.001 pmid: 25544715.

12 Wolf EM, Cox WK. The external rotation test in the diagnosis of adhesive capsulitis. Orthopedics 2010;33. doi:10.3928/01477447-20100329-11. pmid:20506951.

13 Hanchard NC, Goodchild L, Thompson J, O'Brien T, Davison D, Richardson C. Evidence-based clinical guidelines for the diagnosis, assessment and physiotherapy management of contracted (frozen) shoulder: quick reference summary. Physiotherapy 2012;98:117-20. doi:10.1016/.jphysio.2012.01.001 pmid:22507361.

14 Hand C, Clipsham K, Rees JL, Carr AJ. Long-term outcome of frozen shoulder. J Shoulder Elbow Surg 2008;17:231-6. doi:10.1016/j.jse.2007.05.009 pmid:17993282.

15 Maund E, Craig D, Suekarran S, et al. Management of frozen shoulder: a systematic review and cost-effectiveness analysis. Health Technol Assess 2012;16:1-264. doi:10. 3310/hta16110. pmid:22405512.

16 Hanchard NC, Goodchild L, Thompson J, O'Brien T, Davison D, Richardson C. A questionnaire survey of UK physiotherapists on the diagnosis and management of contracted (frozen) shoulder. Physiotherapy 2011;97:115-25. doi:10.1016/.jphysio.2010. 08.012 pmid:21497245

17 Buchbinder R, Green S, Youd JM, Johnston RV. Oral steroids for adhesive capsulitis. Cochrane Database Syst Rev 2006;4:CD006189.pmid:17054278.

18 Uppal HS, Evans JP, Smith C. Frozen shoulder: A systematic review of therapeutic options. World J Orthop 2015;6:263-8. doi:10.5312/wjo.v6.i2.263 pmid:25793166.

19 Page MJ, Green S, Kramer S, et al. Manual therapy and exercise for adhesive capsulitis (frozen shoulder). Cochrane Database Syst Rev 2014;8:CD011275.pmid:25157702.

20 Page MJ, Green S, Kramer S, Johnston RV, McBain B, Buchbinder R. Electrotherapy modalities for adhesive capsulitis (frozen shoulder). Cochrane Database Syst Rev 2014;10:CD011324.pmid:25271097.

21 Bae JH, Park YS, Chang HJ, et al. Randomized controlled trial for efficacy of capsula distension for adhesive capsulitis: fluoroscopy-guided anterior versus ultrasonography-guided posterolateral approach. Ann Rehabil Med 2014;38:360-8. doi: 10.5535/arm.2014.38.3.360. pmid:25024960.

22 Park KD, Nam HS, Kim TK, Kang SH, Lim MH, Park Y. Comparison of Sono-guided Capsular Distension with Fluoroscopically Capsular Distension in Adhesive Capsulitis of Shoulder. Ann Rehabil Med 2012;36:88-97. doi:10.5535/arm.2012.36.1.88. pmid:22506240.

23 Park SW, Lee HS, Kim JH. The effectiveness of intensive mobilization techniques combined with capsular distension for adhesive capsulitis of the shoulder. J Phys Ther Sci 2014:26:1767-70. doi:10.1589/jpts.26.1767. pmid:25435696.

24 Multi-centre randomised controlled trial with economic evaluation and nested qualitative study comparing early structured physiotherapy versus manipulation under anaesthesia versus arthroscopic capsular release for patients referred to secondary care with a primary frozen shoulder (adhesive capsulitis). http://www.isrctn.com/ISRCTN48804508.

25 Scientifically merged acupuncture and robot-assisted technology (SMART) for rehabilitation of frozen shoulder syndrome:First year project verification of acupuncture and evaluation by magnetic resonance imaging examination. https://clinicaltrials.gov/ct2/show/ NCT02076308.

26 A prospective randomized 3-arm trial comparing intra-articular corticosteroid injection versus arthrographic distension versus arthrographic distension plus itra-articular corticosteroid injection in the treatment of adhesive capsulitis. https://clinicaltrials.gov/ct2/ show/NCT01983527.

27 Treatment of adhesive capsulitis: a randomized placebo-controlled trial comparing arthrographic joint distension with steroid and local anaesthetic versus arthrographic join distension with local anaesthetic alone. https://clinicaltrials.gov/ct2/show/NCT02001740.

28 Manipulation under anaesthesia versus arthroscopic capsular release in the treatment of adhesive capsulitis. https://clinicaltrials.gov/ct2/show/NCT01961219.

29 Adhesive capsulitis: prospective analysis of efficacy and financial impact for use of physical therapy in treatment. https://clinicaltrials.gov/ct2/show/NCT02283996.

30 Jones S, Hanchard N, Hamilton S, Rangan A. A qualitative study of patients' perceptions and priorities when living with primary frozen shoulder. BMJ Open 2013;3:e003452. doi: 10.1136/bmjopen-2013-003452. pmid:24078753.

Published by the BMJ Publishing Group Limited. For permission to use (where not already granted under a licence) please go to http://group.bmj.com/group/rights-licensing/ permissions 


\section{Box 5: Recommendations for future research}

Adequately powered randomised controlled trials with:

- Population-Patients with a clinical diagnosis of frozen shoulder

- Studies should specifically address either the pain-predominant phase or the stiffness-predominant phase of frozen shoulder

- The pain predominant phase is the priority, because most patients find this the most trying phase

- Interventions and comparisons:

- Conservative strategies comparing individual and group physiotherapy, home exercises, electrotherapies, and steroid injection in different combinations

- Invasive strategies including distension, manipulation under anaesthesia, and arthroscopic capsular release

- Outcomes-Resolution of pain, improvement of function and quality of life in the short and long term. Patient experience

\section{How patients were involved in the creation of this article}

We asked two patients with frozen shoulder to comment on the manuscript and incorporated their suggestions. They firmly endorsed individualised strategies over rigid pathways in management of symptoms. A patient contributor also recommended further research on effectiveness of a structured multidisciplinary approach with early involvement of general practitioner, orthopaedic surgeon or rheumatologist, physiotherapist, and pain management specialist. 


\section{Tables}

\section{Table 1| Summary of evidence for different treatments of frozen shoulder}

\begin{tabular}{|c|c|c|c|}
\hline Intervention & Type of evidence & Summary of evidence & Evidence of harms \\
\hline $\begin{array}{l}\text { Watchful waiting, with or } \\
\text { without oral analgesia }\end{array}$ & $\begin{array}{l}\text { Systematic review }{ }^{15}: 1 \text { non-randomised } \\
\text { controlled study }(n=77)\end{array}$ & Insufficient evidence & Insufficient evidence \\
\hline \multirow{2}{*}{$\begin{array}{l}\text { Physiotherapy (manual } \\
\text { therapy and exercises, } \\
\text { thermotherapy, and } \\
\text { electrotherapy) }\end{array}$} & $\begin{array}{l}\text { Systematic review of manual therapy } \\
\text { and exercise }{ }^{19}: 30 \text { RCTs, } 2 \\
\text { quasi-RCTs }(n=1836)\end{array}$ & $\begin{array}{l}\text { Insufficient to compare types of manual therapy or } \\
\text { exercise with each other or treatment }{ }^{\star}\end{array}$ & $\begin{array}{l}\text { No serious harms but insufficient } \\
\text { evidence }\end{array}$ \\
\hline & $\begin{array}{l}\text { Systematic review of electrotherapy } \\
\text { (electrical, sound, light, or thermal } \\
\text { energy })^{20}: 19 \text { RCTs }(n=1249)\end{array}$ & $\begin{array}{l}\text { Moderate evidence }{ }^{\star} \text { that } 8 \text { weeks' low level laser } \\
\text { therapy added to exercise benefits pain, function, and } \\
\text { range of movement for mixed-stage frozen shoulder } \\
\text { populations }\end{array}$ & $\begin{array}{l}\text { No serious harms but insufficient } \\
\text { evidence }\end{array}$ \\
\hline Acupuncture & Systematic review ${ }^{15}: 3$ RCTs $(n=509)$ & Insufficient evidence & Insufficient evidence \\
\hline Oral corticosteroid & Systematic review ${ }^{17}: 5$ RCTs $(n=179)$ & $\begin{array}{l}\text { Insufficient evidence to draw firm conclusions, } \\
\text { especially compared with other treatments }\end{array}$ & $\begin{array}{l}\text { Minor and short lived in the trials, } \\
\text { though the known potential risks need } \\
\text { to be considered }\end{array}$ \\
\hline $\begin{array}{l}\text { Intra-articular corticosteroid } \\
\text { injection }\end{array}$ & $\begin{array}{l}\text { Systematic reviews }{ }^{1519}: 6 \text { RCTs } \\
(n=457)\end{array}$ & $\begin{array}{l}\text { Moderate evidence* of benefit on pain, function, and } \\
\text { disability compared with placebo for mixed-stage } \\
\text { frozen shoulder populations, and of enhancement of } \\
\text { effects by combination with manual therapy and } \\
\text { exercise }\end{array}$ & $\begin{array}{l}\text { None reported, but insufficient } \\
\text { evidence to draw conclusions }\end{array}$ \\
\hline $\begin{array}{l}\text { Hydrodilatation with steroid } \\
\text { injection (arthrographic } \\
\text { distension) }\end{array}$ & Systematic review ${ }^{15}: 3$ RCTs $(n=144)$ & $\begin{array}{l}\text { Moderate evidence of benefit on one of two function } \\
\text { and disability outcomes compared with placebo for } \\
\text { mixed-stage frozen shoulder populations. Insufficient } \\
\text { evidence to draw firm conclusions compared with } \\
\text { other treatments }\end{array}$ & $\begin{array}{l}\text { Minor, including procedure related } \\
\text { pain }\end{array}$ \\
\hline $\begin{array}{l}\text { Manipulation of the shoulder } \\
\text { joint under general } \\
\text { anaesthesia }\end{array}$ & Systematic review ${ }^{15}: 4$ RCTs $(n=257)$ & $\begin{array}{l}\text { No evidence of benefit though insufficient evidence } \\
\text { to draw firm conclusions. }\end{array}$ & $\begin{array}{l}\text { None reported, but insufficient } \\
\text { evidence to draw conclusions }\end{array}$ \\
\hline Capsular release & $\begin{array}{l}\text { Systematic review }{ }^{15}: 2 \text { case series } \\
(n=249)\end{array}$ & Insufficient evidence to draw firm conclusions & $\begin{array}{l}\text { No serious harms, but insufficient } \\
\text { evidence to draw conclusions }\end{array}$ \\
\hline
\end{tabular}

$\mathrm{RCT}=$ randomised controlled trial. *GRADE system applied in this review. 


\section{Table 2| Ongoing trials of different treatments of frozen shoulder}

\begin{tabular}{|c|c|c|c|}
\hline Name of trial & $\begin{array}{c}\text { Population } \\
\text { (target sample size) }\end{array}$ & Intervention and comparison & Primary outcome \\
\hline \multirow[t]{3}{*}{$\begin{array}{l}\text { UK Frozen Shoulder Trial (UK FroST), } \\
\text { UK }\end{array}$} & \multirow[t]{3}{*}{$\begin{array}{l}\text { Adults } \geq 18 \text { years old with primary frozen } \\
\text { shoulder, including diabetics }(n=500)\end{array}$} & $\begin{array}{l}\text { 1. Early structured physiotherapy (12 } \\
\text { weeks) }\end{array}$ & \multirow[t]{3}{*}{$\begin{array}{l}\text { Oxford Shoulder Score (OSS) a } \\
12 \text { months after randomisation }\end{array}$} \\
\hline & & $\begin{array}{l}\text { 2. Manipulation under anaesthesia without } \\
\text { arthroscopic capsular release }\end{array}$ & \\
\hline & & $\begin{array}{l}\text { 3. Manipulation under anaesthesia with } \\
\text { arthroscopic capsular release }\end{array}$ & \\
\hline
\end{tabular}

Acupuncture for treatment of Frozen Adults 20-65 years old with frozen shoulder, $\quad 1$. Electroacupuncture and physical shoulder Syndrome (SMART) ${ }^{25}$ Taiwan $\quad(n=60)$ Disabilities of the Arm Shoulder and Hand (DASH); Shoulder Pain

2. Sham electroacupuncture and surgery and Disability Index (SPADI); passive and active range of motion; and musculoskeletal ultrasound at one year

\section{Corticosteroids and/or Arthrographic Adults $\geq 18$ years old with pain and stiffness Distension in the Treatment of Adhesive Capsulitis (CADAC), ${ }^{26}$ Belgium}

Treatment of Adhesive Capsulitis Arthrographic Joint Distension with Local Anaesthetic Alone,${ }^{27}$ Canada

Manipulation under Anaesthesia versus Adults $\geq 18$ years old in the frozen or thawing Capsular Release in the Treatment of phase of frozen shoulder who have tried and Adhesive Capsulitis, ${ }^{28}$ USA failed three months of non-operative treatment or who demand a quicker return to function and will not try non-operative therapy, $(n=50)$

Adhesive Capsulitis: Prospective Analysis of Efficacy and Financial Adults $\geq 18$ years old with frozen shoulder as Impact for Use of Physical Therapy in Treatment, ${ }^{29}$ USA Surgeons, $(n=260)$
1. Arthrographic distension plus intra-articular corticosteroid

2. Arthrographic distension

3. Intra-articular corticosteroid

1. Arthographic distension with triamcinalone plus lidocaine

2. Arthographic distension Lidocaine

SPADI at 4 weeks

1. Manipulation under anaesthesia

DASH 12 months post-operation

2. Arthroscopic capsular release defined Amysiotherapy plus steroid injection
American Shoulder and Elbow Surgeons Standardized Questionnaire one year after enrolment 


\section{Figure}

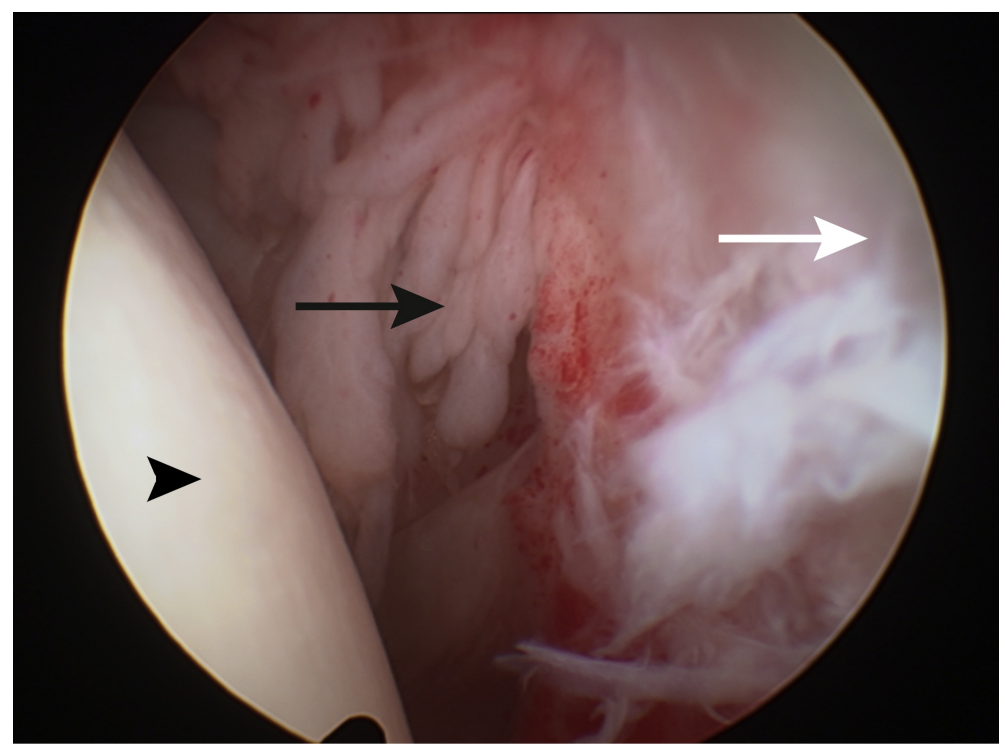

Arthroscopic view of frozen shoulder, showing the humeral head (black arrowhead), glenoid (white arrow), and rotator interval with inflamed and proliferative tissue (black arrow) and site for injection 